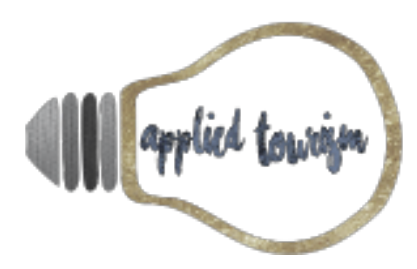

Volume 3, número 3, 2018, p. 54- 64

\title{
ACESSIBILIDADE PARA IDOSOS: Um. Estudo Aplicado ao Parque Sólon de Lucena
}

\author{
Gabriela Patrício Diniz Evangelista \\ Graduanda em Hotelaria e Pesquisadora do Grupo de Cultural \\ e estudo em Turismo (GCET; UFPB) \\ gabrielapdevangelista@outlook.com
}

Felipe Gomes do Nascimento Mestrando em Desenvolvimento e Meio Ambiente e Pesquisador do Grupo de Cultural e estudo em Turismo (GCET; UFPB)

felipegomes.14@hotmail.com

Adriana Brambilla

Phd, Docente e Pesquisadora do Grupo de Cultural e estudo em Turismo (GCET; UFPB) adrianabrambillaa@yahoo.com.br

Elídio Vanzella

Doutor, Docente da ESTÁCIO FACULDADES e Faculdade UNIFUTURO e Pesquisador do Grupo de Cultural e estudo em Turismo (GCET; UFPB) evanzella@yahoo.com.br

Recebido: 06 de setembro, 2018

Aprovado: 27 de outubro, 2018

\section{RESUMO}

O envelhecimento da população brasileira, acompanhando uma tendência mundial, tem apresentado crescimento nas últimas décadas. Neste sentido, o turismo, e em especial o turismo cultural, representa para os idosos o ócio como um tempo de lazer a ser desfrutado de maneira criativa. No entanto, percebe-se que os patrimônios históricos, particularmente os centros históricos brasileiros, possuem obstáculos que dificultam a acessibilidade, como os percursos íngremes, passeios estreitos e degraus. Neste contexto, o presente estudo objetivou avaliar as condições de acessibilidade, para a terceira idade, de um importante patrimônio cultural da cidade de João Pessoa: o Parque Sólon de Lucena. Este estudo caracterizouse por uma pesquisa bibliográfica, exploratória e descritiva com pesquisa de campo. De forma geral, o local apresenta boas condições de acessibilidade por pessoas que possuam alguma dificuldade de mobilidade, mas ainda algumas medidas precisam ser adotadas pelo poder público.

Palavras-chaves: Regionalização do Turismo. Categorização. Santa Catarina. 


\section{INTRODUÇÃO}

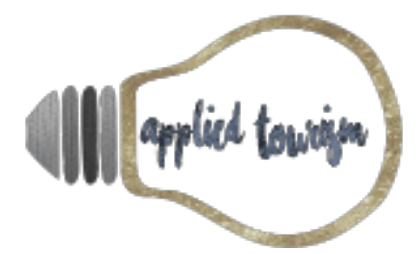

Volume 3, número 3, 2018, p. 54- 64

A discussão sobre o envelhecimento da população tem crescido em diversos estudos, pois a população brasileira vem passando por uma significativa transformação, caracterizada por alterações em seu regime demográfico e estrutura etária (Borges, Campos \& Silva, 2015). Essas mudanças exigem uma nova visão e compreensão sobre o comportamento das pessoas que compõem a chamada terceira idade, pois esse público tem procurado, atualmente, por atividades que os tirem do cotidiano, que lhes permita vivenciar experiências distintas e serem tratados com igualdade perante a sociedade. Dentre as atividades procuradas por esse público a que mais se destaca é o turismo, em especial o turismo cultural. Esse tipo de turismo proporciona o indivíduo conhecer novos modos de vida, isto é, viabiliza a aproximação do turista com as práticas culturais da localidade visitada. No entanto, um dos grandes obstáculos que se coloca ao desenvolvimento desse tipo de turismo são as condições de acessibilidade dos atrativos turísticos, pois há certas características que devem ser observadas para que não somente o público da terceira idade, mas todos os visitantes tenham asseguradas as condições de visitação.

Mediante o exposto, o objetivo desse estudo é avaliar as condições de acessibilidade para a terceira idade de um importante patrimônio cultural da cidade de João Pessoa: o Parque Sólon de Lucena.

\section{FUNDAMENTAÇÃO TEÓRICA}

\section{Terceira idade e turismo cultural}

O envelhecimento da população brasileira está acompanhando uma tendência mundial e tem apresentado crescimento nos últimos anos. Segundo o Instituto Brasileiro de Geografia e Estatística [IBGE] no ano de 2010, 10,8\% da população estavam acima de 60 anos (IBGE, 2016).

Nos dias atuais, as pessoas com mais de 60 anos tornaram-se mais independentes e dispostas a experimentar novas vivências. Neste sentido, o turismo, e, em especial o turismo cultural representa, para os idosos, o ócio como um tempo de lazer a ser desfrutado de maneira criativa e, ao mesmo tempo em que o indivíduo aproveita para "quebrar" a rotina, aprende e se torna mais criativo (Brambilla, Vanzella \& Baptista, 2013).

O turismo cultural pode ser definido como a motivação de viajar para entrar em contato com a história do local, com o patrimônio cultural, promovendo um processo ativo de apropriação e valorização da herança cultural de um determinado local (Duarte, 1994). Pode-se destacar entre os resultados do turismo cultural, a autoconsciência local face aos visitantes, uma vez que o turismo voltado à cultura viabiliza o interesse dos visitantes em conhecer 


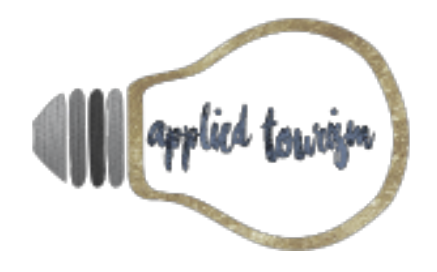

Volume 3, número 3, 2018, p. 54- 64

a cultura dos visitados (Ortiz, 2005; Swarbrooke, 2000). Nesse contexto, percebe-se que os patrimônios históricos, particularmente os centros históricos brasileiros, possuem obstáculos que dificultam a acessibilidade, como os percursos íngremes, passeios estreitos e degraus (Ribeiro, 2014). Dessa forma, há que se observar que mesmo em plenas condições físicas, os turistas idosos necessitam de alguns cuidados e adaptações diferenciadas que permitam a acessibilidade aos atrativos turísticos. Compreendendo a acessibilidade conforme definida pela Associação Brasileira de Normas Técnicas [ABNT], como a possibilidade e condição de alcance, percepção e entendimento para utilização, com segurança e autonomia, de espaços, equipamentos urbanos, edificações, transportes, bem como outros serviços e instalações abertos ao público, de uso público ou privado de uso coletivo, tanto na zona urbana como na rural, por pessoa com deficiência ou mobilidade reduzida (ABNT, 2015).

A promoção da acessibilidade aos patrimônios culturais deve ser proporcionada e incentivada, pois não se pode aceitar a restrição ao acesso das pessoas à história de uma localidade. Assim, é necessário que o poder público e a iniciativa privada encontrem soluções que viabilizem a acessibilidade universal, destacando-se que se faz necessário promover essas ações que respeitando a preservação desses patrimônios.

\section{METODOLOGIA}

Este estudo caracteriza-se como uma pesquisa bibliográfica, exploratória e descritiva com pesquisa de campo. A pesquisa bibliográfica e documental foi realizada com base em livros, artigos científicos e documentos voltados às temáticas da terceira idade, do turismo cultural, da acessibilidade e do Parque Sólon de Lucena.

Para a realização da pesquisa in loco foi elaborado um check-list, instrumento que contemplou os itens a serem considerados na lista de verificação. A construção do check-list exigiu uma atenção especial, pois um instrumento de pesquisa bem elaborado é fundamental para a consecução dos objetivos propostos. Ainda, foi feito um préteste para verificar a aplicabilidade do mesmo e corrigir possíveis erros. O check-list foi desenvolvido com base nas normas e legislações específicas entre as quais: NBR 9050 de 2015 (ABNT, 2015), Estatuto do Idoso, Princípios das Nações Unidas para as Pessoas Idosas, Decreto no 5.296 de 2004 (BRASIL, 2004), Decreto no 5.934 de 2006 (BRASIL, 2006), Lei no 8.842 de 1994 (BRASIL, 1994) e Lei no 13.146 de 2015 (BRASIL, 2015).

A aplicação do check list foi realizada durante o mês de janeiro de 2018, acompanhada por registros fotográficos dos pontos pesquisados no Parque Sólon de Lucena, para permitir uma análise mais completa, considerando que "esses registros possibilitaram um maior detalhamento das análises, pois proporcionam mais objetividade e credibilidade, na medida em que uma imagem fornece a prova tangível da existência de determinado fenômeno" (Mendonça, Barbosa \& Durão, 2007). 


\section{PARQUE SÓLON DE LUCENA}

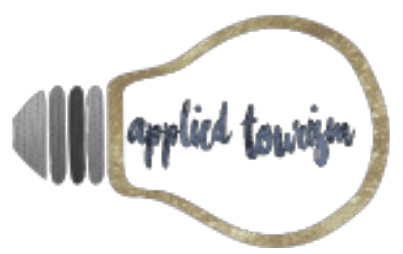

Volume 3, número 3, 2018, p. 54- 64

A cidade de João Pessoa, capital do Estado da Paraíba, considerada uma das cidades mais arborizadas do Brasil e o lugar onde o sol nasce primeiro, foi fundada em 1585, sendo a terceira capital mais antiga do Brasil (Brambilla, Vanzella \& Baptista, 2013). Ainda, segundo os autores, a cidade possui um rico e vasto acervo histórico cultural que lhe permite ser um importante destino turístico voltado ao público da terceira idade, em especial seu Centro Histórico, apontado como patrimônio nacional desde 2007 Esse Centro ocupa uma área de aproximadamente 37 hectares e é composto por igrejas, hotéis, teatros, parques entre outros atrativos que contam a história pessoense. E, é neste cenário que foi escolhido como objeto de estudo o Parque Sólon de Lucena, que, devido à sua importância e beleza natural, caracterizada pelos coloridos ipês e suas majestosas palmeiras imperiais, além de outros atributos, foi tombado conforme Decreto de $n^{\circ}$ 8.653, de 26 de Agosto de 1980 pelo Instituto do Patrimônio Histórico e Artístico da Paraíba (IPHAEP) (Paulino, 2010). Um dos destaques do Parque são seus canteiros projetados por Burle Marx, com várias espécies da Mata Atlântica, com atenção especial ao ipê amarelo, conforme figura 1:

Figura 1: Ipês no Parque Sólon de Lucena, João Pessoa/PB

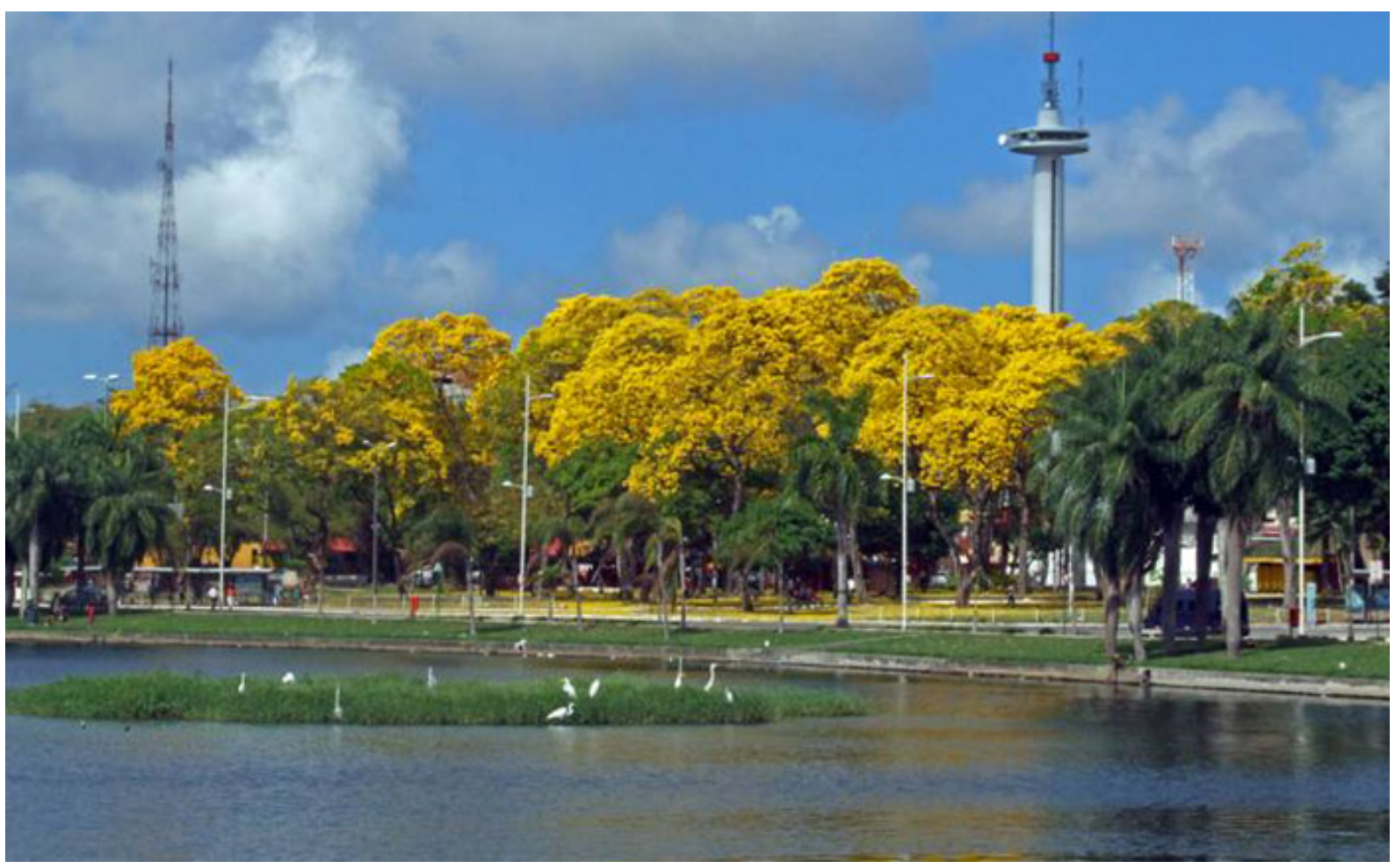

Fonte: Reginaldo Marinho (sd)

Antes de ser conhecido pelo nome de Parque Sólon de Lucena, essa área recebeu outros nomes, como Lagoa Sólon de Lucena e Lagoa dos Irerês, até chegar a sua denominação atual. O Parque Sólon de Lucena inicialmente 


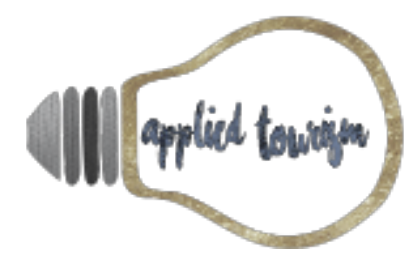

Volume 3, número 3, 2018, p. 54- 64

foi um sítio de propriedade dos jesuítas conhecido na época por "Sítio da Lagoa" ou por "Lagoa dos Irerês" pela grande quantidade desses animais, também conhecidos por marrecos, que habitavam as águas do parque (IBGE, 2015). Sendo este ambiente escolhido pelos jesuítas para se tornar seu lugar de meditação pela tranquilidade e paz que o local oferecia.

No início do século XX, a área da Lagoa era povoada por pessoas de baixo poder aquisitivo, uma vez que o local era desvalorizado por possuir uma densa vegetação remanescente da Mata Atlântica, constituindo obstáculo ao crescimento na direção leste da cidade por ser considerada uma área marcada por um terreno raso e alagadiço (Paulino, 2010). Foi por volta da década de 1922 que o então Sítio da Lagoa se tornou um parque público, passando a ter a denominação atual de Parque Sólon de Lucena, cujo nome é uma homenagem ao então governador do estado Sólon de Lucena, pois em sua administração a área foi urbanizada (IBGE, 2015). Atualmente o Parque é uma região de intenso movimento e marcada pela presença de inúmeros e diversos estabelecimentos comerciais, além de funcionar como uma área de lazer e diversão para a população e para os turistas. O local constitui-se em uma das principais áreas verdes da cidade e por sua localização, no centro de João Pessoa, é palco de diversos movimentos sociais e eventos culturais.

\section{RESULTADOS E DISCUSSÕES}

Com base nas pesquisas bibliográficas, documentais, nos levantamentos obtidos através do check list e dos registros fotográficos, foram realizadas as análises e a descrição dos achados.

Durante a pesquisa pôde-se observar a existência de calçadas em toda parte externa e interna do Parque Sólon de Lucena. Pôde-se observar também, que a calçada encontra-se em perfeito estado de conservação, possui largura adequada com piso trepidante e antiderrapante, assegurando autonomia e segurança ao público da terceira idade (Figura 2), bem como às pessoas com deficiência ou mobilidade reduzida, atendendo assim às conformidades recomendadas pela NBR 9050:2015.

Figura 2: Calçada Interna e Externa

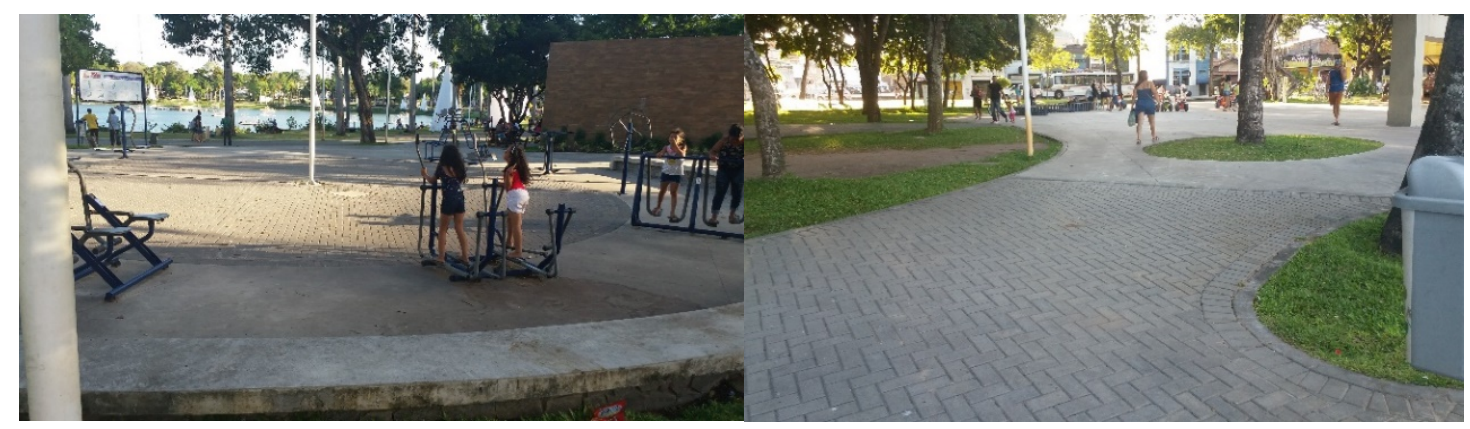

Fonte: autores, 2018.

Evangelista, G. P. D.; Nascimento, F. G.; Brambilla, A.; Vanzella, E. (2018). ACESSIBILIDADE PARA IDOSOS: Um Estudo Aplicado ao Parque Sólon de Lucena. Applied Tourism, 3(3), 54-64. 


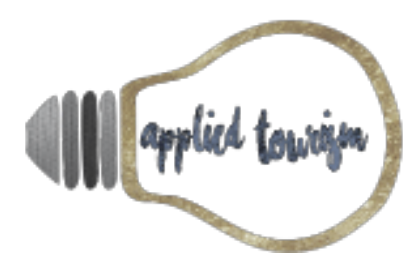

Volume 3, número 3, 2018, p. 54- 64

No que se refere aos banheiros, constatou-se sua existência em rota acessível para pessoas com mobilidade reduzida como idosos, pessoas com deficiência e obesas. Verificou-se a correta largura da porta bem como a existência do espaço para que um usuário de cadeira de rodas possa se movimentar com a cadeira. Outro ponto positivo, encontrado no local, foi a presença das barras de apoio sem apresentar deformações permanentes na parte de trás e na lateral da bacia sanitária (Figuras 3 e 4). Assim como, foi observada a existência de lavatório dentro do boxe. A maçaneta não possui formato de fácil pega recomendada pelas normas técnicas, exigindo firmeza, precisão ou torção do pulso para seu acionamento. Sendo assim, atende parcialmente às normas de acessibilidade.

Figura 3: Banheiro Acessível

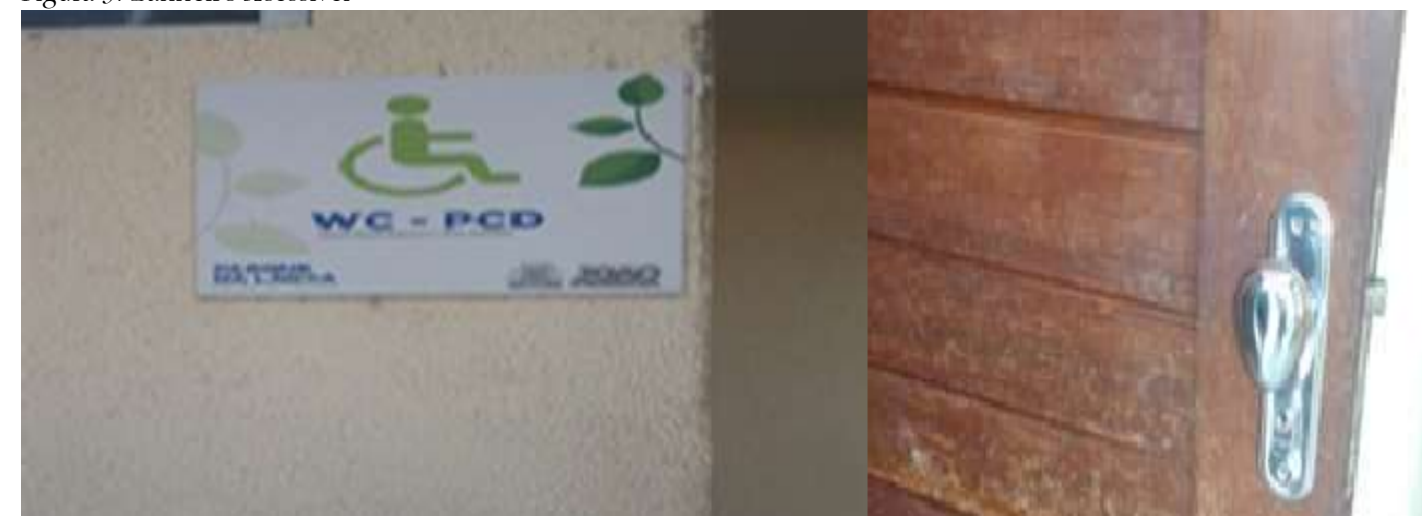

Fonte: autores, 2018.

Figura 4: Banheiro Acessível e Lavabo

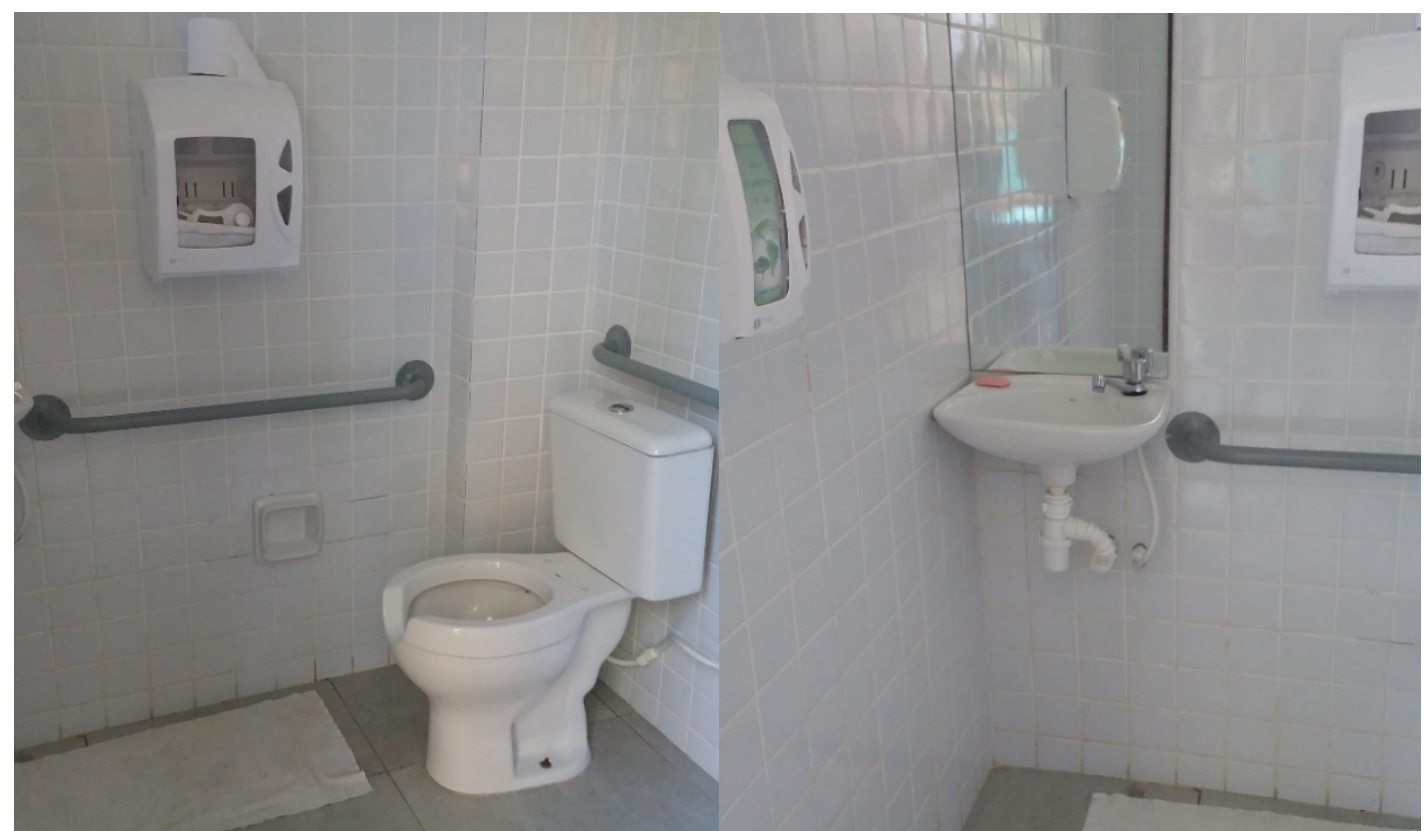

Fonte: autores, 2018. 


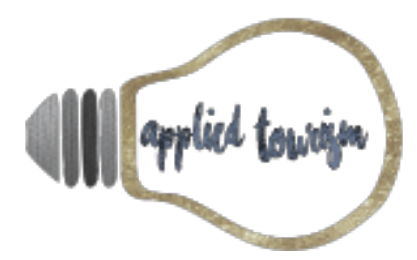

Volume 3, número 3, 2018, p. 54- 64

Outro ponto analisado foi o acesso ao anel externo do Parque (Figura 5) com existência de rampa, permitindo ingresso ao Parque Sólon de Lucena por pessoas com mobilidade reduzida como idosos, pessoas com deficiência e pessoas obesas, bem como a presença de piso alerta utilizado para identificar locais acessíveis. O piso possui superfície regular, firme, estável e antiaderente, atendendo às conformidades recomendadas pela NBR 9050:2015.

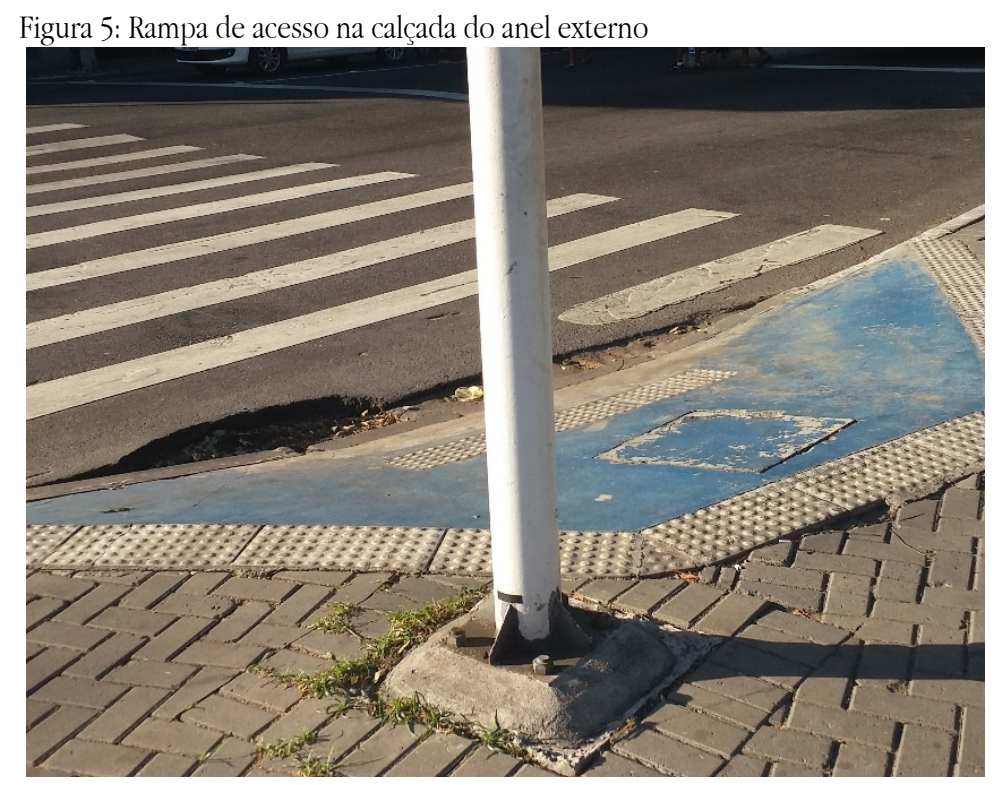

Fonte: autores, 2018.

Constatou-se a existência de pier adentrando a lagoa, construído em madeira e que foi utilizado por um curto período de tempo após a inauguração do Parque Sólon de Lucena. Alguns meses depois o pier foi desativado por oferecer risco de quedas à população. Portanto, no momento, não atendendo às necessidades do público em geral e muito menos às pessoas idosas. 


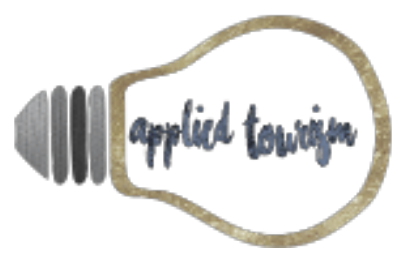

Volume 3, número 3, 2018, p. 54- 64

Figura 6: Rampa de acesso ao pier da lagoa

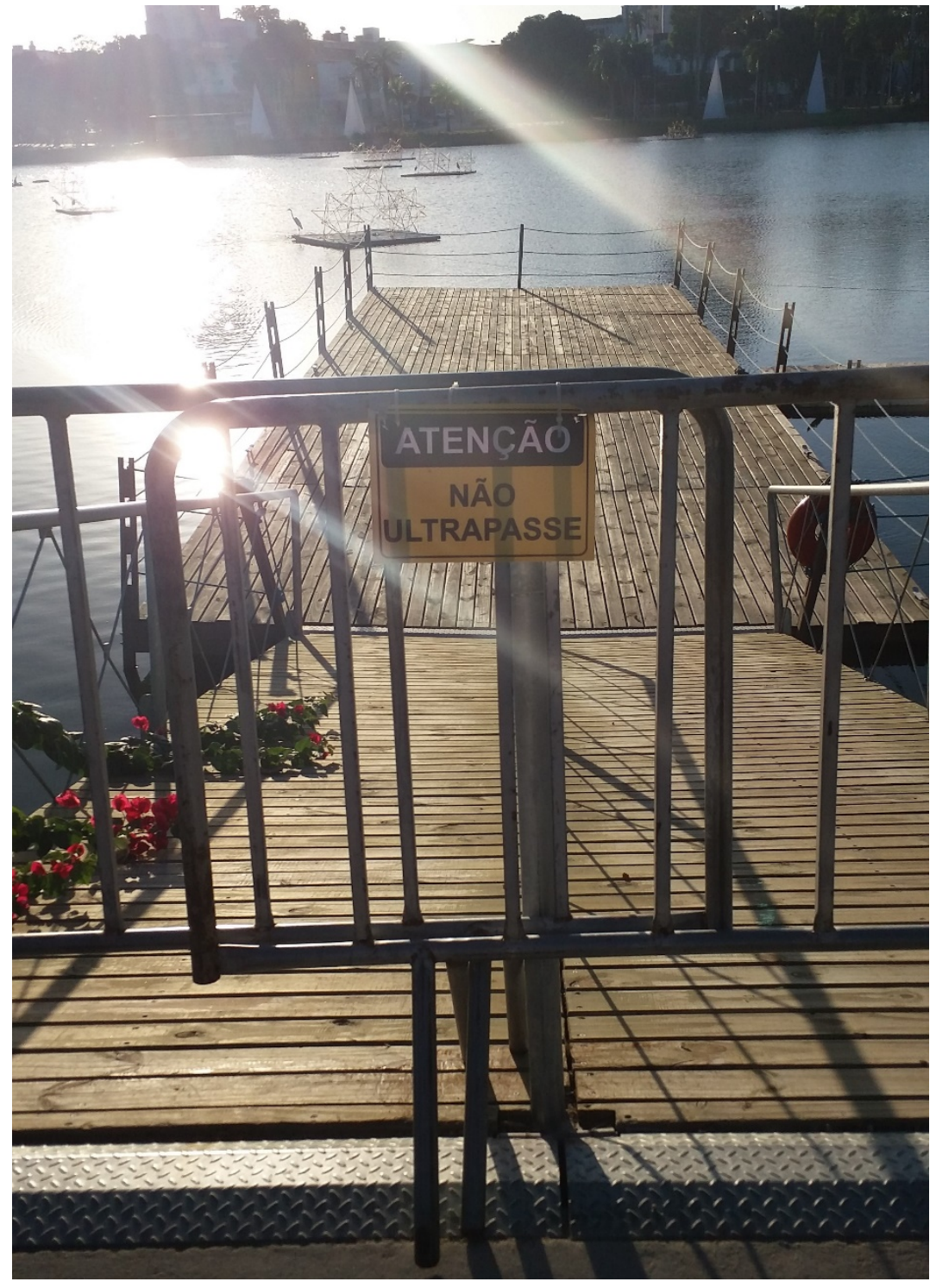

Fonte: autores, 2018.

\section{Aplicabilidade da acessibilidade para idosos nos estudos do turismo}

Espera-se que os resultados obtidos, nesse estudo, bem como as discussões apresentadas possam fomentar debates entre a sociedade, autoridades públicas e a iniciativa privada, levando-os a buscar soluções que viabilizem a acessibilidade nos diversos equipamentos de uso turístico e social.

Partindo das principais análises realizadas no Parque Sólon de Lucena, objeto de estudo dessa pesquisa, pôde-se observar que o local apresenta pontos positivos no que se refere à acessibilidade para o público idoso, embora ainda demande medidas que garantam a acessibilidade total. No que se refere à academia, deseja-se que o trabalho incentive novas pesquisas voltadas à acessibilidade do público idoso, para que esse possa desfrutar com 


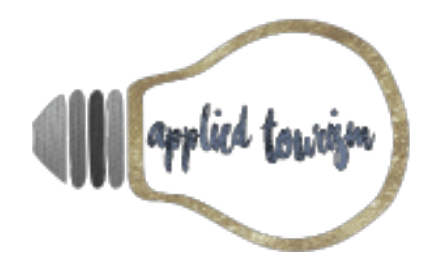

Volume 3, número 3, 2018, p. 54- 64

segurança e autonomia, tendo em vista que o Parque Sólon de Lucena, além de cartão postal da cidade, também é um importante patrimônio cultural pessoense.

Neste sentido, o trabalho visa contribuir para que o setor público esteja consciente das necessidades de melhoria no Parque e ainda para que adote políticas públicas que atendam a essas necessidades em todos os patrimônios culturais da cidade. A aplicação do check list na pesquisa de campo foi essencial para a obtenção dos resultados, pois atuou como um importante instrumento para a averiguação das condições de acessibilidade do Parque Sólon de Lucena para o turista idoso que visita a cidade de João Pessoa, assim como para aqueles que residem na cidade, e, muitas vezes, encontram-se impedidos de usufruir dos patrimônios. Essa pesquisa tem também, entre suas contribuições, o incentivo a novos estudos na área da acessibilidade nos centros históricos pessoenses e servir como um alerta sobre a questão da inclusão social, através da acessibilidade, ao mostrar a importância dos patrimônios para a sociedade e, ao mesmo tempo, atentar para as dificuldades que parte dos cidadãos enfrenta ao visitar esses locais. Não se pode discutir inclusão social, sem se passar pelo debate da acessibilidade, pois a falta de condições de acesso ao patrimônio cultural de uma cidade constitui-se em um forte obstáculo ao exercício da cidadania.

\section{CONSIDERAÇÕES FINAIS}

As mudanças na estrutura etária no Brasil têm apontado para um novo segmento: o das pessoas acima de sessenta anos, e essas alterações afetam diretamente o turismo. Esse segmento, denominado terceira idade, se mostra repleto de necessidades a serem atendidas, uma vez que as pessoas idosas buscam atividades diversas, com destaque para aquelas que permitem vivenciar novos modos de vida e o conhecimento de culturas diferentes. Neste sentido, o turismo cultural torna-se uma opção muito procurada por esse público, mas para que as pessoas possam usufruir das atividades oferecidas pelo turismo cultural é imprescindível que diversas medidas sejam adotadas, entre as quais, aquelas que visem assegurar a acessibilidade nos locais de visitação.

Diante desse cenário, o presente trabalho teve como objetivo geral avaliar as condições de acessibilidade para a terceira idade de um importante patrimônio cultural da cidade de João Pessoa: o Parque Sólon de Lucena, cuja história está intimamente ligada aos modos de vida da cidade.

Para atender a esse propósito realizou-se um estudo bibliográfico, exploratório e descritivo com pesquisa de campo, que possibilitou verificar as condições de acessibilidade do Parque. De forma geral, o local apresenta boas condições de acessibilidade para os idosos, oferecendo condições de uso por pessoas que apresentam dificuldades de mobilidade. 


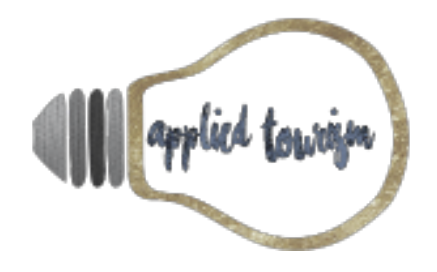

Volume 3, número 3, 2018, p. 54- 64

Diante do exposto, espera-se que esse estudo possa contribuir para que não somente os idosos, mas todas as pessoas com deficiência e/ou mobilidade reduzida, possam usufruir desse patrimônio histórico, para que as deficiências encontradas possam ser sanadas e os aspectos positivos sejam divulgados com o intuito de que outros patrimônios históricos possam adotar medidas que possibilitem a visitação de todos os públicos.

\section{REFERÊNCIAS}

Associação Brasileira de Normas Técnicas (2015). NBR 9050: 2015 -Acessibilidade a edificações, mobiliário, espaços e equipamentos urbanos. Rio de Janeiro: ABNT.

Borges, G. M., Campos, M. B. \& Silva, L. G. D. C. (2015). Transição da estrutura etária no Brasil: oportunidades e desafios para a sociedade nas próximas décadas. In: R. Ervatti, G. M. Borges \& A. P. Jardim (Orgs.). Mudança Demográfica no Brasil no Início do Século XXI. Subsídios para as projeções da população. Rio de Janeiro: IBGE.

Brambilla, A.; Vanzella, E.; Baptista, M. M. T. R. (2013). Cultural Tourism in the city of joão pessoa: a look focused on elderly tourist.Academia.edu. Disponivel em: <https://www.academia.edu /12318682 /CULTURAL _TOURISM_IN_THE_CITY_OF_JO\%C3\%830_PESSOA_a_look_focused_on_elderly_tourist $>$. Acesso em: $\overline{1} 8$ jan. 2018.

Brasil. Decreto n 5.296 de 2 de dezembro de 2004 (2004). Regulamenta as Leis no ${ }^{\circ}$ 10.048, de 8 de novembro de 2000, que dá prioridade de atendimento às pessoas que especifica, e 10.098, de 19 de dezembro de 2000, que estabelece normas gerais e critérios básicos para a promoção da acessibilidade das pessoas portadoras de deficiência ou com mobilidade reduzida, e dá outras providências.

Brasil. Decreto n 5.934 , de 18 de outubro de 2006 (2006). Estabelece mecanismos e critérios a serem adotados na aplicação do disposto no art. 40 da Lei no 10.741, de 1 o de outubro de 2003 (Estatuto do Idoso), e dá outras providências.

Brasil. Lei no 13.146, de 6 de julho de 2015 (2015). Institui a Lei Brasileira de Inclusão da Pessoa com Deficiência (Estatuto da Pessoa com Deficiência).

Brasil. Lei no 8.842 , de 4 de janeiro de 1994 (1994). Dispõe sobre a política nacional do idoso, cria o Conselho Nacional do Idoso e dá outras providências.

Duarte, A. M. P. (1994). Educação Patrimonial: Guia para professores, educadores, monitores de museu e tempo livres. (Edition) Lisboa, Portugal: Editora.

Instituto Brasileiro de Geografia e Estatística. (2015). Parque Sólon de Lucena : João Pessoa, PB. Recuperado em 10 de março, 2018, de https://biblioteca.ibge.gov.br /biblioteca-catalogo.htmllid=442093\&view=detalhes

Instituto Brasileiro de Geografia e Estatística. (2016). IBGE Populações. Projeções e estimativas da população do Brasil e das Unidades da Federação. Disponivel em: < http://www.ibge.gov.br/apps/populacao/projecao/index.html>. Acesso em: 07 set 2016.

Mendonça, J.R.C., Barbosa, M.L.A., Durão, A.F. (2007). Fotografias como um recurso de pesquisa em marketing: o uso de métodos visuais no estudo de organizações de serviços. Revista administração contemporânea, 11(3). p.57-81.

Ortiz, R. (2005). Um outro território: ensaios sobre mundialização. (Edition). São Paulo, SP: Olho D ’ Água. 


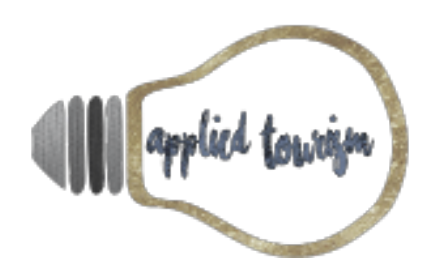

Volume 3, número 3, 2018, p. 54- 64

Paulino, M.C.P. (2010) História e Urbanização: Liminaridades no Parque Sólon de Lucena, João Pessoa/PB. 2010. I Encontro Nacional da Associação Nacional de Pesquisa e Pós-Graduação em Arquitetura e Urbanismo. Rio de Janeiro.

Ribeiro, S. B. (2014). Mobilidade e Acessibilidade em Centros Históricos. Recuperado em 10 de fevereiro, 2018, de htp://www.portal.iphan.gov.br

Swarbrooke, J. (2000). Turismo sustentável: conceitos e impacto ambiental. Vol 1. São Paulo, SP: Aleph. 